\title{
Airway Complications after Lung Transplantation: Long-Term Outcome of Silicone Stenting
}

\author{
Arve Sundset $^{\mathrm{a}, \mathrm{b}} \quad$ May Brit Lund ${ }^{\mathrm{a}}$ Gunnar Hansen ${ }^{\mathrm{a}, \mathrm{b}} \quad \varnothing_{\text {ystein Bjørtuft }}{ }^{\mathrm{a}}$ \\ Johny Kongerud ${ }^{a, d}$ Odd Ragnar Geiran c, d \\ ${ }^{a}$ Department of Respiratory Medicine, ${ }^{\mathrm{b}}$ Interventional Centre, ${ }^{\mathrm{C}}$ Department of Thoracic and Cardiovascular \\ Surgery, and ${ }^{\mathrm{d}}$ Faculty Division Rikshospitalet, Oslo University Hospital, Rikshospitalet, Oslo, Norway
}

\section{Key Words}

Airway complications · Airway stenosis - Airway stenting •

Lung transplantation $\cdot$ Silicone stents

\begin{abstract}
Background: Airway complications remain a significant cause of morbidity after lung transplantation. The majority of the centres that have published their results have used metal stents. Objectives: We report the long-term outcome of silicone stenting and subsequent stent removal in lung transplant recipients with stenotic airway complications. Method: From 1990 to 2008, 279 patients received 88 single, 170 double, and 21 heart-and-lung transplantations. Of 470 anastomoses at risk, 44 airway complications developed and were treated in 35 patients. Six lesions were treated with $\mathrm{Nd}$ :YAG laser and balloon dilatations only. Thirty-two silicone stents of Hood or Dumont type were inserted in 27 patients. Results: Symptoms were relieved and $\mathrm{FEV}_{1}$ increased in all patients (median 0.7 litres, range $0.1-1.8$ litres, $p<0.0001$ ). In 8 patients, stents had to be repositioned or reinserted, in 19 patients only one insertion and one removal procedure were necessary. One patient suffered a serious complication with haemorrhage and pneumonectomy, 3 patients had minor airway wall injuries resolving spontaneously. Six patients
\end{abstract}

died with the stents from causes not related to the airway complications. Twenty-five stents could be removed after a median of 6 months (range 1-22) in 21 patients, and 22 airways remained patent. Median $\mathrm{FEV}_{1}$ was 2.3 litres immediately after stent removal, and remained 2.3 litres after 24 months. Conclusion: Stenotic airway complications after lung transplantation can be successfully treated with silicone stents, which can ultimately be removed, leaving a patent airway.

Copyright $\odot 2012$ S. Karger AG, Basel

\section{Introduction}

Airway complications may present significant problems after lung transplantation despite improvements in graft preservation and surgical techniques [1-3]. The major cause of airway complications is related to airway ischaemia, as the donor bronchus is dependent on collateral perfusion from the pulmonary circulation since the bronchial arteries are usually not revascularized. Total dehiscence of the airway anastomosis is a rare but often a fatal complication [4]. More common are partial dehiscence and bronchial stenosis, the latter caused by formation of excessive granulation tissue, necrosis or hypertro-

\section{KARGER}

Fax +4161306 1234 E-Mail karger@karger.ch www.karger.com

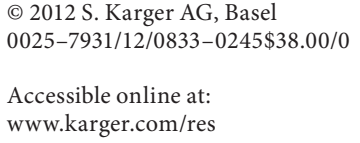

Arve Sundset

Department of Respiratory Medicine

Rikshospitalet, $\mathrm{Pb}$. 4956 Nydalen

NO-0424 Oslo (Norway)

Tel. +47 23072 515, E-Mail asundset@ ous-hf.no 
phic scar tissue. Airway obstruction may cause loss of lung function, mucus retention and recurrent infections. Dynamic airway instability or bronchial malacia of the transplanted airways may develop at a later stage, causing airway collapse, especially during coughing, and often there is a combination of airway stenosis and dynamic collapse [5].

Bronchial stenosis after lung transplantation can sometimes be treated with laser (YAG laser or argon plasma coagulation) and dilatation with a balloon or a rigid bronchoscope, but the stenosis frequently recurs after dilatation, making insertion of a stent necessary. The majority of centres that have published their results have chosen self-expandable metal stents to treat post-transplantation airway complications [1, 2, 6-9]. These stents are easy to deploy using flexible bronchoscopy and fluoroscopy; they are flexible, and can be used almost regardless of airway anatomy as they conform well to distortions and curves within the airway [10]. The major disadvantage of metal stents is the difficulty to remove them once they have been in situ for more than 1-2 months, as the metal mash is covered by airway epithelium or granulation tissue. Metal stents may also cause excessive granuloma formation obstructing the airway, and they may fracture $[7,9]$.

Insertion of silicone stents is more cumbersome as it requires rigid bronchoscopy and general anaesthesia. The affected airway must be relatively straight and the stenosis must be dilated before the procedure since the silicone stent is not flexible. The surface of silicone stents is smooth, which makes them more apt to migrate, but they can easily be removed or repositioned at a later stage. Silicone stents are, however, more prone to occlusion by encrustation of secretions [11].

At our institution, we have chosen silicone stents whenever possible when treating stenotic post-transplantation airway complications, with the aim to remove the stents, when the remodelling or scarring of the airway has subsided.

We reviewed our database to assess the long-term outcome of this treatment algorithm, presenting lung function expressed as $\mathrm{FEV}_{1}$, over a 2-year period following stent removal.

\section{Material and Methods}

All lung transplant recipients have been registered prospectively since our lung transplantation programme was launched, with data regarding complications, treatment and lung function. Our lung transplantation database for scientific purposes was ap- proved by the Institutional Review Board. Patients with airway complications who needed treatment were extracted from this database, and their journals were made accessible in order to review symptoms, indications for treatment and lung function data, in more detail.

\section{Indications for Stenting}

A combination of clinical symptoms consistent with airway obstruction, deteriorating lung function and endoscopic confirmation of airway stenosis (central airway calibre visually assessed to be less than $8-10 \mathrm{~mm}$ in diameter) was required before stenting was considered. These symptoms included increasing cough, recurrent infections and dyspnoea. The endoscopic findings of airway stenosis included excessive necrosis, granulation tissue or scar tissue formation and local retention of secretions.

\section{Organ Preservation and Surgical Technique}

From 1990 to 1999, donor lung preservation was done by Flo$\operatorname{lan}{ }^{\circledR}$ infusion in the pulmonary artery and antegrade flush with cold Papworth pneumoplegia solution with additional submersion in iced saline. Since 2000, antegrade flush with cold Perfa$\operatorname{dex}^{\circledR}$ solution has been used, supplemented with immersion of the lungs at $4^{\circ} \mathrm{C}$ in the same solution.

Unilateral procedures were performed through thoracotomy and bilateral procedures through midline sternotomies. All procedures were performed after heparin administration on partial or full cardiopulmonary bypass.

Reconstruction of the airway was performed with continuous polypropylene stitch until 1996. Thereafter interrupted stitches on the cartilaginous part and running polydioxanone (PDS) stitches on the membranous part were used. Soft tissues were respected and anastomosis was performed on the cartilaginous ring proximal to the upper lobe bronchus or above the tracheal carina. An intercostal bundle wrap was used initially on unilateral procedures but was later abandoned. No bronchial artery revascularization was performed.

\section{Patients}

In the period 1990-2008, 279 patients received 88 unilateral lung, 170 bilateral, sequential double-lung, and 21 heart-and-lung transplants at our institution. In 35 patients, 44 airway complications were identified and treated, i.e. 9.4\% of the 470 anastomoses at risk. Four patients had early dehiscence of the anastomosis, 1 was immediately fatal, 2 were successfully re-operated on, and 1 patient was successfully treated with a metal stent. Two airway lesions were primarily considered to be bronchomalacia and were treated with metal stent insertions as the primary procedure. The remaining 38 stenotic airway lesions were treated according to our treatment algorithm and constitute the material described in this study.

Assessment of Airway Complications

The patients were routinely investigated with bronchoscopies at 2, 4 and 12 weeks after transplantation, and for clinical indications such as infections, productive cough or deteriorating lung function. After stent insertions, surveillance bronchoscopies were performed regularly to inspect the stents and to detect stentrelated complications. Following stent removal, control bronchoscopies were performed 1-2 months after removal, and later for clinical indications. 

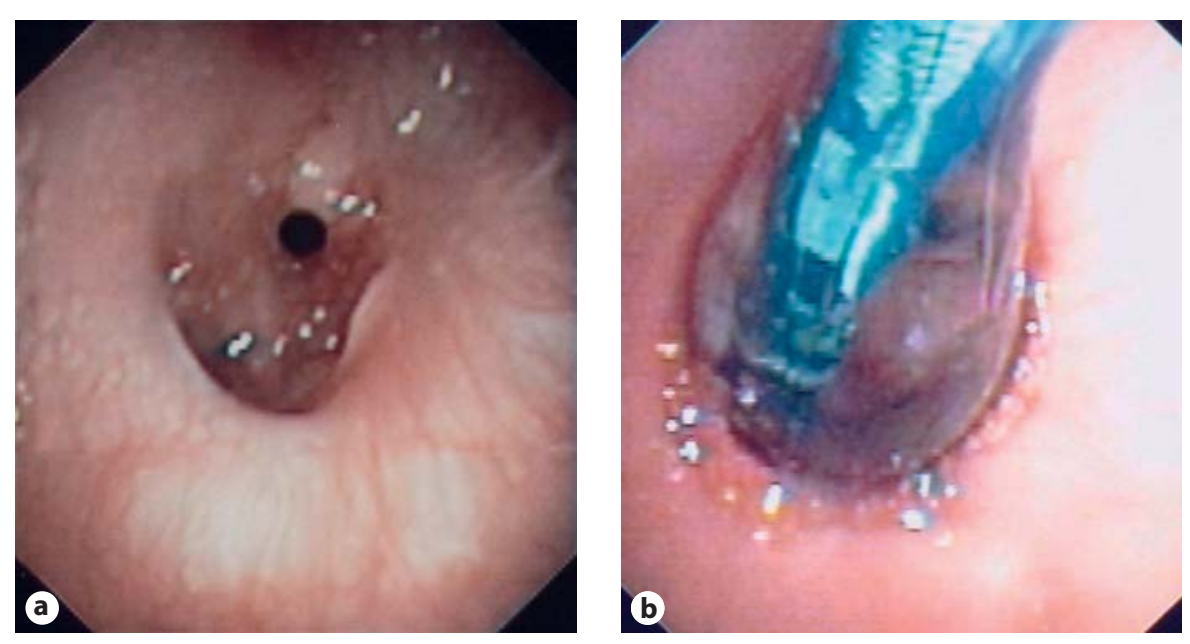

Fig. 1. a A severe stenosis of the bronchus intermedius developing 2-3 months following lung transplantation; the lumen is reduced to approximately $2 \mathrm{~mm}$ in diameter. To the left: the orifice of the right upper lobe bronchus. b Following radial $\mathrm{Nd}$ :YAG laser incisions, the bronchus intermedius is dilated with a dilatation balloon of $10 \times 20 \mathrm{~mm}$, the balloon is inflated to 7-8 atm in $60 \mathrm{~s}$. c A silicon stent (Hood Laboratories) $10 \times 20 \mathrm{~mm}$ is inserted into the bronchus intermedius. d Patent bronchus intermedius 12 months after stent removal.
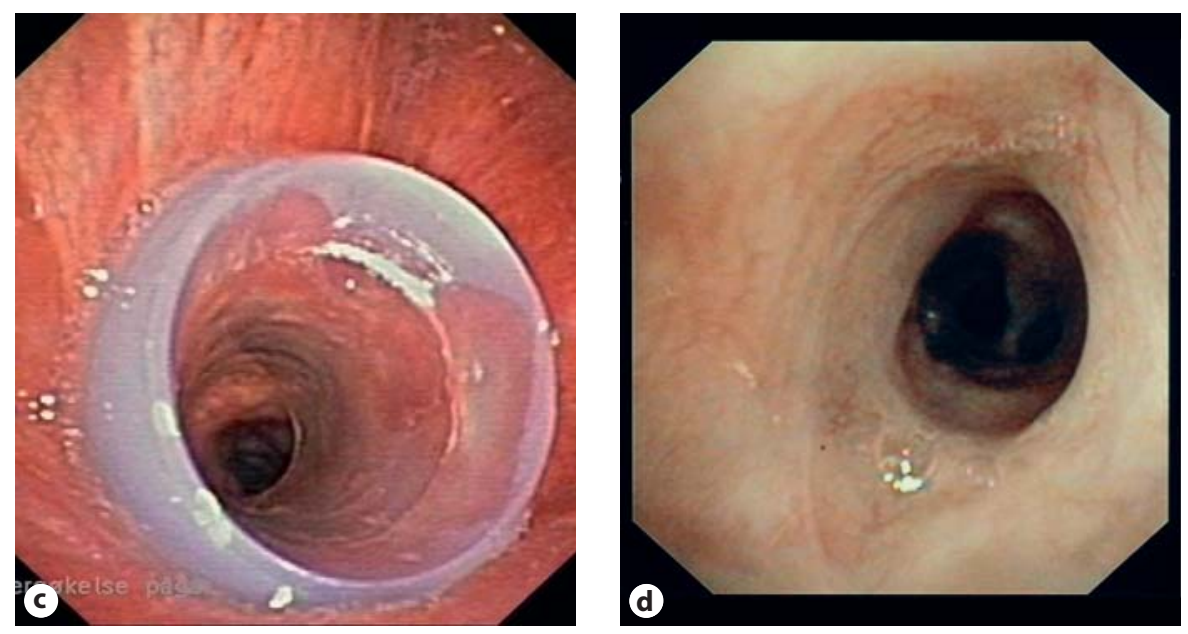

\section{Lung Function Measurements and Assessment of Airway} Patency

Spirometry was carried out according to the guidelines of the European Respiratory Society (ERS) using the Jaeger Master Lab (Eric Jaeger, Würzburg, Germany). The reference values recommended by the ERS were used [12]. To evaluate the effect of stent insertion, the last $\mathrm{FEV}_{1}$ performed prior to intervention was compared to the mean of the two best recordings after the intervention. In 6 of the patients, spirometry was not performed prior to stent insertions for various reasons; in most cases because it was too early after transplantation and the patients were in a critical condition and not fit to perform spirometry, and in 1 patient, a thoracic hernia made spirometry inadvisable. In another patient, spirometric data from long-term outcome analysis after stent removal were excluded due to non-reproducible flow-volume loops. This patient had developed dynamic airway collapse in both main bronchi, which made it impossible to obtain reproducible spirometry results.

To evaluate airway patency following removal of the stents, the airways were inspected endoscopically, and lung function was monitored at regular intervals. The last $\mathrm{FEV}_{1}$ performed before stent removal was compared to measurements performed at 1-24 months following stent removal. Some patients had stents insert- ed on both sides, and in these patients, data following removal of the first stent will be missing in the analysis.

\section{Stent Insertion Techniques}

Following Nd:YAG laser treatment and balloon dilatations, silicone stents, Hood stents (Hood Laboratories, Pembroke, Mass., USA) or Dumont stents were placed during rigid bronchoscopy with rigid forceps (fig. 1). One patient received a hybrid Alveolus stent, a fully silicone-covered nitinol stent (Alveolus Inc., Charlotte, N.C., USA). In the aftercare, all patients inhaled nebulized saline twice daily to prevent stent encrustations.

\section{Stent Removal}

The decision when to remove the stents was based on a clinical assessment of the stenotic process in the airways. During control bronchoscopies following stent insertion, the transplanted airways were inspected for signs of necrosis and scar tissue. The degree of airway pathology and healing was assessed visually, both in the surroundings of the stented airway, and also on the contralateral side in patients with double-lung transplants. Stent removal was usually performed during flexible bronchoscopy under local anaesthesia. 
Fig. 2. Overview of the treatment and long-term outcome of stenotic post-transplantation airway complications at our institution.

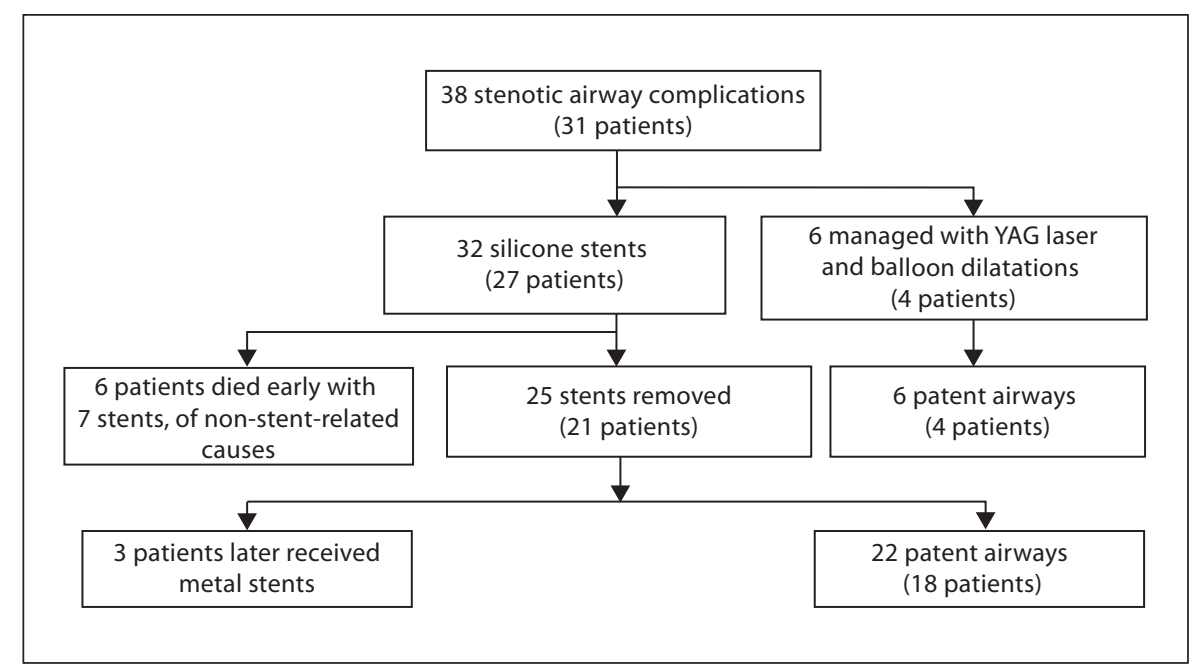

Statistical Methods

Comparison of lung function before and after stent placement and removal was done with the non-parametric Wilcoxon matched-pairs test (SPSS).

\section{Results}

Thirty-eight stenotic airway complications were treated in 31 patients. Six airway stenoses were manageable with balloon dilatations and Nd:YAG laser alone, and 32 silicone stents were placed in 27 patients (fig. 2). Six of these patients died with 7 functioning stents from causes not related to the airway complications. In the remaining 21 patients, 25 stents were removed after a median of 6 months (range 1-22). Twenty-two of the stented airways remained patent after stent removal, and lung function was stable during the 24 months following stent removal. A moderate degree of airway collapse was observed in 4 of these patients, but no further intervention was considered necessary although 2 of these had a moderate reduction in $\mathrm{FEV}_{1}$ after stent removal. Three patients later received metal stents, 2 due to bronchomalacia, and 1 patient, due to recurrent scar tissue and stenosis.

Three patients developed bronchiolitis obliterans syndrome (BOS) and died within the first year after stent removal. One patient died of sepsis and multi-organ failure 1 year after stent removal.

Table 1 shows the clinical characteristics, locations of the stents, time to first airway intervention, and the number of procedures performed. In the majority of patients (19 patients, 70\%), not more than 1 stent insertion and 1
Table 1. Clinical characteristics and airway stenting in 27 lung transplant recipients

$\begin{array}{ll}\text { Clinical characteristics } & \\ \text { Gender (M:F) } & 16: 11 \\ \text { Median age (range), years } & 53(21-61) \\ \text { Double lung transplant } & 19 \\ \text { Single lung transplant (right:left) } & 7(4: 3) \\ \text { Heart and lung transplant } & 1\end{array}$

Time after transplantation to first intervention

Median time for silicone stents (range), days 97 (32-243)

Median time for metal stents (range), days 350 (13-822)

\begin{tabular}{lr}
\hline Location of silicone stents & \\
Left main bronchus & 19 \\
Right main bronchus & 5 \\
Right bronchus intermedius & 7 \\
Trachea & 1 \\
\hline Silicone stenting procedures & 88 \\
Insertion and/or reinsertion & 47 \\
Repositioning & 5 \\
Removal & 36
\end{tabular}

Other procedures

Laser and balloon dilatation $\quad 26$

Metal stent insertions

26

removal procedure were performed. In 8 patients, stents had to be repositioned or removed and reinserted. In 1 patient a total of 8 stent procedures, and 4 procedures with Nd:YAG laser and balloon dilations were necessary. In total, 88 silicone stenting procedures and 26 additional procedures with $\mathrm{Nd}: Y A G$ laser and balloon dilations were performed. 
Presenting symptoms were relieved in all patients, and $\mathrm{FEV}_{1}$ increased with a median of 0.7 litre, from 1.6 to 2.3 litres, range $0.1-1.8$ litres, $p<0.0001$ (fig. 3 ). The patients with the most severe obstruction prior to stenting had the largest functional improvement. For the patients who had received bilateral lung transplantation, stenting almost normalized lung function, as $\mathrm{FEV}_{1}$ increased to $83.5 \%$ (56-101\%) of predicted (median, range). When the stents were removed after a median of 6 months (1-22 months), the airways were patent and $\mathrm{FEV}_{1}$ did not change significantly: mean $\mathrm{FEV}_{1}$ before and after removal was 2.3 litres (fig. 4). The observation time after stent removal was more than 24 months in the long-term survivors. Lung function remained unchanged during the 24-month follow-up period, median $\mathrm{FEV}_{1}$ was 2.3 litres immediately after stent removal and after 24 months.

The stents were sometimes obstructed with inspissated secretions and had to be cleared during bronchoscopy. Formation of moderate amounts of granulation tissue at the distal end of the stents occurred frequently, but rarely caused any significant obstruction or need for endo-

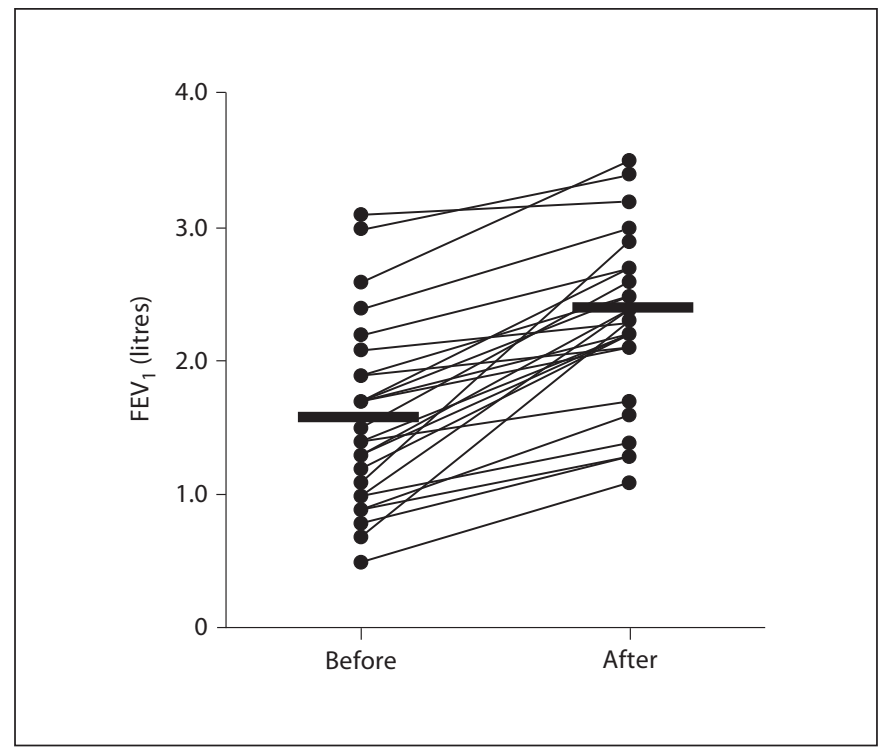

Fig. 3. Lung function, presented as $\mathrm{FEV}_{1}$, before and after silicone stent insertion. The $\mathrm{FEV}_{1}$ values are from the last spirometry before stenting, and values after stenting are the mean of the two best spirometries performed after stenting.
Fig. 4. Lung function, expressed as $\mathrm{FEV}_{1}$, before and after removal of the silicone stents, and during the following 24 months. Apart from 2 patients who had a moderate reduction in $\mathrm{FEV}_{1}$ due to dynamic airway collapse, and 3 patients, who later received metal stents due to malacia $\left({ }^{*}\right)$, lung function remained stable during 24 months. There were 4 deaths during the observation period: 3 patients died of BOS and 1 of sepsis and multiorgan failure $(\dagger)$.

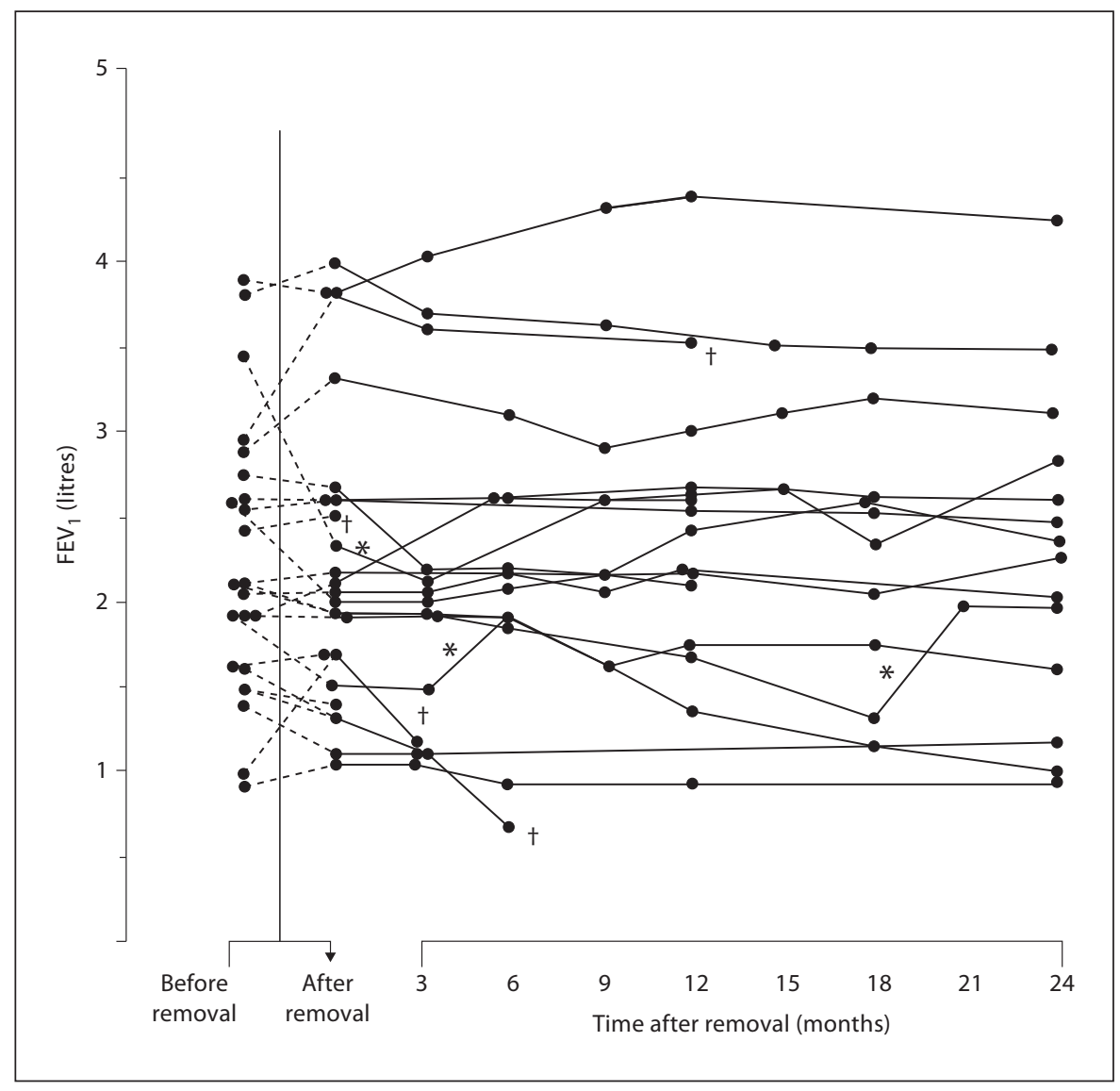


scopic intervention, and ceased spontaneously following stent removal. One serious complication occurred in 1 patient, where the stent was initially successfully inserted, but subsequent pulling of a suture with forceps caused a massive haemorrhage, resulting in an emergency pneumonectomy. In 3 patients, minor perforations of the bronchial wall caused by the rigid bronchoscope or forceps healed spontaneously.

\section{Discussion}

Airway complications in lung transplant recipients occur during the first weeks or months after transplantation, and require treatment when there is a clinically important decline in lung function or when retention of secretions and recurrent infections occur. Sometimes bronchoscopic interventions like balloon dilatation and laser photocoagulation can control these complications, but more often than not, the stenosis recurs, making repeated procedures or insertion of stents necessary $[6,13]$.

We report excellent long-term outcome of silicone stenting of stenotic airway complications following lung transplantation. In the vast majority $(88 \%)$ of our patients, the silicone stents could ultimately be successfully removed after a few months, leaving a patent airway. During the 24-month observation period, lung function, expressed as $\mathrm{FEV}_{1}$, remained unchanged. These results confirm that our treatment strategy to use silicone stents whenever possible can be successful and support the findings of two papers recently published by Thistlethwaite et al. [3] and Dutau et al. [14], who also demonstrated excellent results after silicone stenting and subsequent removal. They reported patency of the airways after stent removal to be excellent in the majority of their patients, but spirometry data during follow-up were not presented.

All our patients had symptom relief after stent insertion, and their $\mathrm{FEV}_{1}$ increased by a mean of 0.7 litres per stent. This is not unexpected, but confirms the indication of endoscopic intervention. In the patients who received double-lung transplants, $\mathrm{FEV}_{1}$ increased to a mean of 83.5\% (range $56-101 \%$ ) of predicted.

In our material, we consider only 2 patients to be treatment failures. In these 2, airway stenosis recurred after more than 2 years of stenting, and several attempts to remove the stents failed. One of these patients kept the silicone stent; the other patient eventually had a metal stent inserted.

Three of our patients developed BOS and died a few months after stent removal, but we do not consider this to be related to the stent treatment. The frequency of BOS-related deaths in our material (3 out of 27 patients) is in accordance with the International Society of Heart and Lung Transplantation registry data, and conforms approximately to what could be expected in a population of lung transplant recipients of such magnitude within the first 3 years after transplantation [15]. Whether airway ischaemia or development of airway complications is associated with development of BOS remains controversial, and our material is not of such magnitude that we can comment on this issue.

Of the 32 stenotic lesions stented with silicone stents, 14 later even developed dynamic airway collapse in the same area. The majority of the patients with dynamic airway collapse had only mild clinical symptoms, and could be managed without further endoscopic intervention. Only 3 of the patients later received metal stents due to dynamic airway collapse (fig. 4).

As other groups have also described, dynamic airway collapse seems to take longer to develop than bronchial stenosis. Most bronchial stenoses develop within the first 2-6 months whereas malacia usually takes about a year or more to develop [5]. One of our patients received a metal stent only 13 days after transplantation, but this patient had excessive dynamic airway collapse not only of the transplanted but also of the native airways, hence we suggest this patient had an undiagnosed airway collapse prior to transplantation.

In our opinion, patients with severe dynamic airway collapse who display retention of secretions and recurrent infections or debilitating dyspnoea despite conservative treatment can be candidates for stenting. Silicone stents are more likely to migrate if the lesion is primarily a segment with dynamic airway collapse with no stenosis to hold the stent in place. Silicone stenting in patients with benign central airway collapse is associated with a high rate of stent-related adverse events and the need for multiple interventions [16]. Nevertheless, in the largest prospective study on silicone stenting of severe tracheobronchomalacia to date, Ernst et al. [17] reported a marked improvement in symptoms, in health-related quality of life and in functional status in the majority of their patients. The use of metal stents remains controversial in benign conditions, and the US Food and Drug Administration have published a warning letter in 2005, discouraging the use of metal stents in benign disease due to complications [18].

Silicone stents do have some disadvantages, which are clearly documented in this study. Repeated procedures under general anaesthesia are sometimes necessary when 
the stent migrates, or when the stenotic lesion changes configuration over time and the stent has to be repositioned. In our material, however, the majority of the patients $(70 \%)$ only needed 1 stent insertion and 1 removal procedure, the latter under local anaesthesia. The stents sometimes get obstructed with incrusted secretions, which require clearing by bronchoscopy, and they can initiate the formation of obstructing granulation tissue. They also require experience in rigid bronchoscopy, and instrumentation with a rigid bronchoscope and rigid forceps in ischaemic, necrotic airways in lung transplant recipients is not without risk of complications. In our material, however, only 1 serious (severe haemorrhage), and 3 moderate complications (minor perforations of the bronchial wall) occurred in 88 stenting procedures. Twentysix additional procedures with Nd:YAG laser and balloon dilations were without any complications.

The timing of the stent removal was sometimes difficult, as the airway covered by the stents could not be inspected directly. If the stents were removed prematurely, the stenosis would recur and subsequently additional stent insertion procedures were required. The degree and duration of the airway pathology was quite variable among the different patients, hence the great variability of the time from stent insertion to removal from 1 to 22 months. However, in our experience, visual inspection of the transplanted airways surrounding the stents and of the contralateral transplanted airways was usually sufficient to decide on the timing of stent removal, as $70 \%$ of our patients had only 1 stent insertion and 1 removal procedure. Patients were followed with surveillance bronchoscopies at 1- to 2-month intervals after stent insertion. In 2 of our patients, the airways did not heal, and permanent stenting proved necessary.

Several authors have reported good immediate and long-term results with metal stents, which are easy to in- sert, but difficult to remove $[5,19]$. We chose a priori to use silicone stents, as we hoped to be able to remove the stents at a later stage since removable stents are considered preferable in benign conditions $[10,20]$. Insertion of metal stents is easier and can be done even under local anaesthesia. These stents are, however, usually not removable, and will have to stay in the transplanted airways for many years in the long-term survivors, and there is concern about metal fatigue and stent fractures in the long term $[5,13,21]$. They can also cause formation of granulation tissue and halitosis [22]. In the largest series on self-expandable metallic stents in lung transplant recipients published to date, Gottlieb et al. [9] found a 52\% incidence of re-stenosis, and new bacterial airway colonization in $40 \%$ of their patients. The authors concluded that the long-term outcome of metal stenting is unfavourable, and suggested that removable or biodegradable stents could be preferable.

The $9 \%$ incidence of airway complications in our material is well within the range of what is reported in most other larger series of lung transplant recipients $[3,5,23$, 24]. Attempts have been made at reducing the incidence of airway complications by revascularization of the bronchial arteries, but these techniques prolong the operation time and have not been adopted by many centres as longterm outcome of the procedure is uncertain $[25,26]$. Modifications of the surgical techniques of airway anastomosis have also been reported, and in a recent publication, Weder et al. [27] demonstrated impressive results with their surgical technique.

In conclusion, the long-term outcome of our treatment strategy to insert silicone stents in lung transplant recipients with airway stenosis is favourable since the stents can be removed in the majority of patients after a few months, leaving a patent airway.

\section{References}

1 Herrera JM, McNeil KD, Higgins RS, et al: Airway complications after lung transplantation: treatment and long-term outcome. Ann Thorac Surg 2001;71:989-993.

-2 Chhajed PN, Malouf MA, Tamm M, et al: Interventional bronchoscopy for the management of airway complications following lung transplantation. Chest 2001;120:1894-1899.

- 3 Thistlethwaite PA, Yung G, Kemp A, et al: Airway stenoses after lung transplantation: incidence, management, and outcome. J Thorac Cardiovasc Surg 2008;136:15691575.

Long-Term Outcome of Silicone Stenting
4 Schafers HJ, Haydock DA, Cooper JD: The prevalence and management of bronchial anastomotic complications in lung transplantation. J Thorac Cardiovasc Surg 1991; 101:1044-1052.

$\checkmark 5$ Burns KE, Orons PD, Dauber JH, et al: Endobronchial metallic stent placement for airway complications after lung transplantation: longitudinal results. Ann Thorac Surg 2002;74:1934-1941.

6 Chhajed PN, Malouf MA, Tamm M, et al: Ultraflex stents for the management of airway complications in lung transplant recipients. Respirology 2003;8:59-64.
7 Kshettry VR, Kroshus TJ, Hertz MI, et al: Early and late airway complications after lung transplantation: incidence and management. Ann Thorac Surg 1997;63:15761583.

8 Lonchyna VA, Arcidi JM Jr, Garrity ER Jr, et al: Refractory post-transplant airway strictures: successful management with wire stents. Eur J Cardiothorac Surg 1999;15:842849

9 Gottlieb J, Fuehner T, Dierich M, et al: Are metallic stents really safe? A long-term analysis in lung transplant recipients. Eur Respir J 2009;34:1417-1422. 
-10 Wood DE, Liu YH, Vallières E, et al: Airway stenting for malignant and benign tracheobronchial stenosis. Ann Thorac Surg 2003; 76:167-172.

-11 Sonett JR, Keenan RJ, Ferson PF, et al: Endobronchial management of benign, malignant, and lung transplantation airway stenoses. Ann Thorac Surg 1995;59:1417-1422.

$\checkmark 12$ Quanjer PH, Tammeling GJ, Cotes JE, et al: Lung volumes and forced ventilatory flows. Report Working Party Standardization of Lung Function Tests, European Community for Steel and Coal. Official Statement of the European Respiratory Society. Eur Respir J Suppl 1993;16:5-40.

-13 Ernst A, Feller-Kopman D, Becker HD, et al: Central airway obstruction. Am J Respir Crit Care Med 2004;169:1278-1297.

-14 Dutau H, Cavailles A, Sakr L, et al. A retrospective study of silicone stent placement for management of anastomotic airway complications in lung transplant recipients: Shortand long-term outcomes. J Heart Lung Transplant 2010;29:658-664.

15 Christie JD, Edwards LB, Aurora P, et al: Registry of the International Society for Heart and Lung Transplantation: TwentyFifth Official Adult Lung and Heart/Lung Transplantation Report-2008. J Heart Lung Transplant 2008;27:957-969.
6 Murgu SD, Colt HG: Complications of silicone stent insertion in patients with expiratory central airway collapse. Ann Thorac Surg 2007;84:1870-1877.

17 Ernst A, Majid A, Feller-Kopman D, et al: Airway stabilization with silicone stents for treating adult tracheobronchomalacia: a prospective observational study. Chest 2007 132:609-616.

18 Shultz D: FDA public health notification Complications from metallic tracheal stents in patients with benign airway disorders. Washington, FDA, 2005.

19 Susanto I, Peters JI, Levine SM, et al: Use of balloon-expandable metallic stents in the management of bronchial stenosis and bronchomalacia after lung transplantation. Chest 1998;114:1330-1335.

20 Ernst A, Silvestri GA, Johnstone D: Interventional pulmonary procedures: Guidelines from the American College of Chest Physicians. Chest 2003;123:1693-1717.

21 Hramiec JE, Haasler GB: Tracheal wire stent complications in malacia: implications of position and design. Ann Thorac Surg 1997; 63:209-212.
22 Madden BP, Loke TK, Sheth AC: Do expandable metallic airway stents have a role in the management of patients with benign tracheobronchial disease? Ann Thorac Surg 2006;82:274-278.

23 Moreno P, Alvarez A, Algar FJ, et al: Incidence, management and clinical outcomes of patients with airway complications following lung transplantation. Eur J Cardiothorac Surg 2008;34:1198-1205.

24 Santacruz JF, Mehta AC: Airway complications and management after lung transplantation: ischemia, dehiscence, and stenosis. Proc Am Thorac Soc 2009;6:79-93.

25 Couraud L, Baudet E, Martigne C, et al: Bronchial revascularization in double-lung transplantation: a series of 8 patients. Bordeaux Lung and Heart-Lung Transplant Group. Ann Thorac Surg 1992;53:88-94.

26 Daly RC, Tadjkarimi S, Khaghani A, et al: Successful double-lung transplantation with direct bronchial artery revascularization. Ann Thorac Surg 1993;56:885-892.

27 Weder W, Inci I, Korom S, et al: Airway complications after lung transplantation: risk factors, prevention and outcome. Eur J Cardiothorac Surg 2009;35:293-298. 